\title{
Validity of Immunoglobulin M Anti Salmonella typhi Serologic Test in Childhood Typhoid Fever
}

\author{
Hilda Marsela, ${ }^{1}$ Djatnika Setiabudi, ${ }^{2}$ Agnes Rengga Indrati ${ }^{3}$ \\ ${ }^{1}$ Faculty of Medicine Universitas Padjadjaran, ${ }^{2}$ Department of Child Health Faculty of Medicine \\ Universitas Padjadjaran/Dr. Hasan Sadikin General Hospital Bandung, ${ }^{3}$ Department of Clinical \\ Pathology Faculty of Medicine Universitas Padjadjaran/Dr. Hasan Sadikin General Hospital
} Bandung

\begin{abstract}
Background: Typhoid fever, which mostly affects children, remains a major health problem in developing countries. Early diagnosis will help the management and thus, reduce morbidity and mortality. However, a rapid diagnostic test that detects the presence of immunoglobulin M (IgM) directed towards Salmonella typhi (S. typhi) antigen remains controversial despite its popularity. This study was aimed to assess the validity of IgM anti S. typhi serologic test in childhood typhoid fever.

Methods: This retrospective diagnostic test, used blood culture as gold standard. Forty-one typhoid fever children with fever of 1-14 days admitted to Dr. Hasan Sadikin General Hospital Bandung from 2013 to 2015 were recruited. Diagnosis of typhoid fever is made clinically. Data were analyzed by Receiver Operating Characteristic (ROC) curve and diagnostic test.

Results: Forty one children diagnosed with typhoid fever, 37 were positive for IgM anti S. typhi, but only 18 were positive for S. typhi in blood culture. IgM anti S. typhi (cut-off $\geq 4$ ) test had an Area Under the Curve (AUC) of $59 \%$, sensitivity of $100 \%$ and specificity of $17.39 \%$. IgM anti S. typhi with cut-off $>8$ showed the highest AUC with sensitivity of $55.56 \%$ and specificity of $73.68 \%$.

Conclusions: IgM anti $S$. typhi test of cut-off $>8$ performs better than cut-off $\geq 4$ in terms of AUC.. [AMJ.2017;4(1):138-42]
\end{abstract}

Keywords: Children, diagnostic test, immunoglobulin M anti Salmonella typhi, typhoid fever

\section{Introduction}

Typhoid fever remains a major global health problem. The endemic population in low and middle-income countries was about 5.6 billion, the risk-adjusted overall incidence was 214 per 100,000 individuals, and the risk-unadjusted overall incidence was 371 per 100,000 individuals in $2010 .{ }^{1}$ In Indonesia, typhoid fever remains endemic. Estimated national prevalence is $1.6 \%$ (range: $0.3-3 \%$ ), while West Java has a higher rate $(2.14 \%)$. School-aged children are the most vulnerable group and have the highest prevalence $(1.9 \%){ }^{2}$

A rapid, accurate diagnostic method is crucial for prompt and effective treatment and, moreover, to prevent complications, as complications may occur if disease is not treated immediately. ${ }^{3}$ Furthermore, Rapid diagnostic test (RDT), a serologic test which detects the presence of immunoglobulin M (IgM) specific to bacterial antigen Salmonella typhi (S. typhi), is popular in recent years; however, it remains controversial due to the variability of its performance (sensitivity and specificity) among many studies and countries. ${ }^{4-11}$ There are no studies about this diagnostic test both in Indonesia and children group. Hence, this study was conducted to assess the validity of IgM anti S. typhi serologic test in childhood typhoid fever.

\section{Methods}

The target population of the study was all children diagnosed with typhoid fever. All children aged 1 to 14 years admitted to the Department of Child Health Dr. Hasan Sadikin General Hospital Bandung, from April 2013 to March 2015 diagnosed with typhoid fever

Correspondence: Hilda Marsela, Faculty of Medicine, Universitas Padjadjaran, Jalan Raya Bandung-Sumedang Km.21, Jatinangor, Sumedang, Indonesia, Phone: +6281213338130 Email: hilda.marsela@gmail.com 
were accessible for the study. Inclusion criteria were children with fever of 1-14 days who were clinically diagnosed with typhoid fever, inpatient at the Department of Child Health Dr. Hasan Sadikin General Hospital Bandung, and tested for both blood culture and IgM anti S. typhi. Exclusion criteria were children who were diagnosed with typhoid fever and other infectious diseases at the same time, immunocompromise patients, being in immunosuppressant therapy during the disease, or severe malnutrition.

Ethical approval for the study was granted by the Health Research Ethics Committee of Dr. Hasan Sadikin General Hospital Bandung, no. LB.04.01/A05/EC/236/VII/2015. Samples were selected using the total sampling method. A minimum sample of 41 was calculated from sample size formula for diagnostic study.

This study was a diagnostic test. Data were collected from medical records. Furthermore, analysis was performed using ROC curve and diagnostic test (2x2 table). The ROC curve measured AUC, as well as sensitivity, specificity, predictive values and likelihood ratios of corresponding cut-off values of $\operatorname{IgM}$ anti S. typhi serologic test. Diagnostic test (2x2 table) of IgM anti S. typhi serologic test, using blood culture as a gold standard, measured sensitivity, specificity, predictive values, likelihood ratios and accuracy of the test.

\section{Results}

Out of 264 children diagnosed with typhoid fever admitted from April 2013 to March 2015, 152 children met the inclusion criteria; however, 40 did not perform blood culture, 6 did not perform IgM anti $S$. typhi serologic test, and 65 did not perform both tests. Thus, the remaining 41 were selected as study subjects.

Additionally, specimen collection time had a median of day 7 and mode of day 7 . Characteristics of the study subjects (Table 1) demonstrated that the mean age at onset of disease was 7.15 years old and mode 6 years old (middle childhood). Antibiotics have been used in $68.3 \%$ of study subjects before hospital admission. Its proportion is the highest in middle childhood $(48.8 \%)$. IgM anti $S$. typhi serologic test (median of cut-off $>7$ and mode of cut-off $>10$ ) was positive in $90.2 \%$ of cases, the in middle childhood $(63.4 \%)$ and on day 7 of sample collection (31.7\%). Blood culture

Table 1 Characteristics of Study Subjects

\begin{tabular}{lc}
\hline \multicolumn{1}{c}{ Characteristic } & $\mathbf{N}(\mathbf{\%})$ \\
\hline Sex & $20(48.8)$ \\
Male & $21(51.2)$ \\
Female & \\
Age (years) & $2(4.9)$ \\
$\quad$ Toddler (1-2) & $10(24.4)$ \\
Preschooler (3-5) & $27(65.9)$ \\
Middle childhood (6-11) & $2(4.9)$ \\
Young teen (12-14) & \\
Antibiotics & $28(68.3)$ \\
Yes & $2(4.9)$ \\
No & $11(26.8)$ \\
Unidentified & \\
IgM anti S. typhi result (cut-off value) & $37(90.2)$ \\
Positive $(\geq 4)$ & $4(9.8)$ \\
Negative $(<4)$ & $18(43.9)$ \\
Blood culture & $23(56.1)$ \\
Positive & \\
Negative &
\end{tabular}


Table 2 Diagnostic Test (2x2 table) of IgM anti S. typhi Serologic Test

\begin{tabular}{lcccc}
\hline & & \multicolumn{2}{c}{ Gold Standard: Blood Culture } & \multirow{2}{*}{ Total } \\
\cline { 3 - 4 } & & Positive & Negative & \\
\hline IgM Anti S. typhi Serologic & Positive $(\geq 4)$ & 18 & 19 & 37 \\
Test & Negative $(<4)$ & 0 & 4 & 4 \\
& Total & 18 & 23 & 41 \\
\hline
\end{tabular}

was positive in $43.9 \%$ of cases, the highest in middle childhood $(36.6 \%)$ and on day 7 of sample collection $(24.4 \%)$.

Moreover, IgM anti $S$. typhi serologic test (cut-off $\geq 4$ ) demonstrated an AUC of 0.59 (95\% CI, range: $0.42-0.74)$ when being analyzed by $2 \times 2$ table (Table 2 ). The test was calculated to be $100 \%$ sensitive $(95 \% \mathrm{CI}$, range: $81.47-100.00 \%)$ and $17.39 \%$ specific (95\% CI, range: $4.95-38.78 \%$ ). The positive and negative predictive values were $48.65 \%$ (95\% CI, range: $31.92-65.6 \%$ ) and $100 \%$ (95\% CI, range: $39.76-100.00 \%$ ), respectively. The positive and negative likelihood ratios were 1.21 (95\% CI, range: $1.00-1.46)$ and 0.00 (95\% CI), respectively. The disease prevalence was $43.90 \%$ (95\% CI, range: $28.47-60.25 \%$ ), besides, the test had an accuracy of $53.65 \%$.

In contrast to $2 \times 2$ table, ROC curve (Figure 1) analysis demonstrated that the AUC of IgM anti S. typhi serologic test (cut-off $\geq 4$ ) was $62.9 \%$ (95\% CI, range: 45.5-78.1\%).

The cut-off values with their corresponding sensitivity and specificity were compared
(Table 3). The highest AUC was found on cutoff value $>8(95 \% \mathrm{CI}$, range: $>6$ to $>9)$ with sensitivity of $55.56 \%$ (95\% CI, range: $30.8-$ $78.5 \%)$ and specificity of $73.68 \%$ (95\% CI, range: $48.8-90.9 \%$ ).

\section{Discussion}

The proportion of disease had no significant difference on the sex group as demonstrated in a prior study. ${ }^{13}$ However, it is similar to another study, ${ }^{2}$ which demonstrates that the middle childhood (6-11 years) group has the highest proportion of disease.

Positivity rates of $\operatorname{IgM}$ anti S.typhi serological tests were considered good. The highest rate was noted on day 7 , presumably because of an increasing IgM response, which is similar to previous observations. ${ }^{5,8}$ Positivity rate of blood culture was considered low. In contrast to a previous study which stated that the best period for blood culture is day $<7$ of disease, ${ }^{14-16}$ the highest rate was noted on day 7. Low positivity rates of blood culture, which

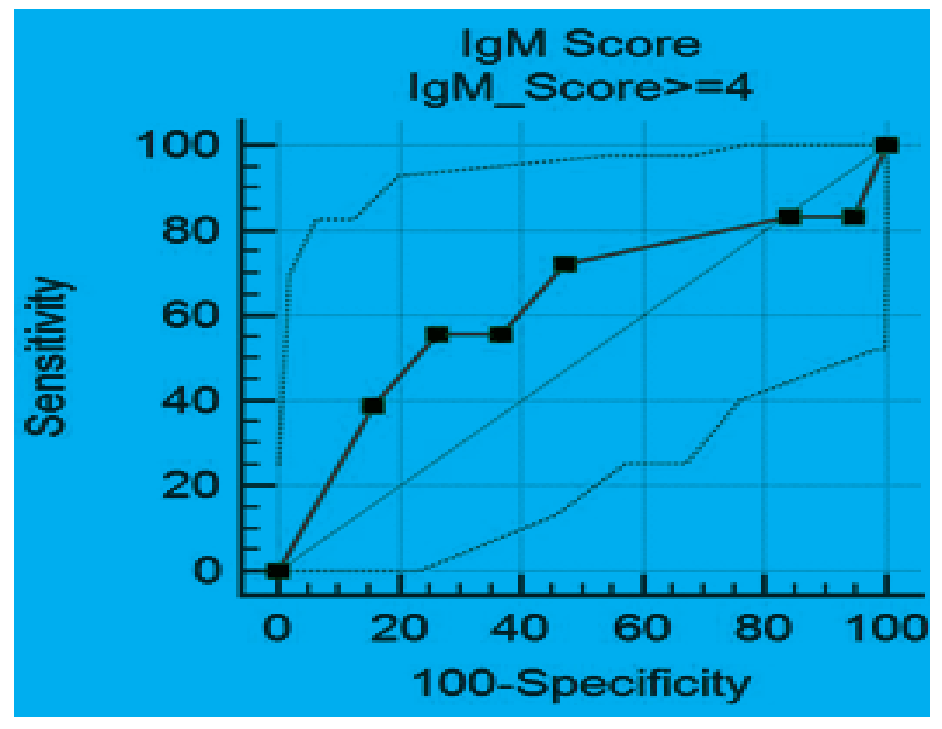

Figure 1 Receiver Operating Characteristic (ROC) Curve 
Table 3 Comparison of Cut-Off Values with Corresponding Sensitivity, Specificity, Positive Likelihood Ratio and Negative Likelihood Ratio

\begin{tabular}{|c|c|c|c|c|}
\hline Cut-Off Values & $\begin{array}{c}\text { Sensitivity (\%) } \\
(95 \% \mathrm{CI})\end{array}$ & $\begin{array}{c}\text { Specificity (\%) } \\
(95 \% \mathrm{CI})\end{array}$ & $\begin{array}{c}\text { +LR } \\
(95 \% \mathrm{CI})\end{array}$ & $\begin{array}{c}-\mathrm{LR} \\
(95 \% \mathrm{CI}) \\
\end{array}$ \\
\hline$\geq 4$ & $\begin{array}{c}100 \\
(81.5-100.0)\end{array}$ & $\begin{array}{c}0 \\
(0.0-17.6)\end{array}$ & $\begin{array}{c}1 \\
(1.0-1.0)\end{array}$ & \\
\hline$>4$ & $\begin{array}{c}83.33 \\
(58.6-96.4)\end{array}$ & $\begin{array}{c}5.26 \\
(0.1-26.0)\end{array}$ & $\begin{array}{c}0.88 \\
(0.7-1.1)\end{array}$ & $\begin{array}{c}3.17 \\
(0.4-27.7)\end{array}$ \\
\hline$>5$ & $\begin{array}{c}83.33 \\
(58.6-96.4)\end{array}$ & $\begin{array}{c}15.79 \\
(3.4-39.6)\end{array}$ & $\begin{array}{c}0.99 \\
(0.7-1.3)\end{array}$ & $\begin{array}{c}1.06 \\
(0.2-4.6)\end{array}$ \\
\hline$>6$ & $\begin{array}{c}72.22 \\
(46.5-90.3)\end{array}$ & $\begin{array}{c}52.63 \\
(28.9-75.6)\end{array}$ & $\begin{array}{c}1.52 \\
(0.9-2.7)\end{array}$ & $\begin{array}{c}0.53 \\
(0.2-1.2)\end{array}$ \\
\hline$>7$ & $\begin{array}{c}55.56 \\
(30.8-78.5)\end{array}$ & $\begin{array}{c}63.16 \\
(38.4-83.7)\end{array}$ & $\begin{array}{c}1.51 \\
(0.7-3.1)\end{array}$ & $\begin{array}{c}0.70 \\
(0.4-1.3)\end{array}$ \\
\hline$>8$ & $\begin{array}{c}55.56 \\
(30.8-78.5)\end{array}$ & $\begin{array}{c}73.68 \\
(48.8-90.9)\end{array}$ & $\begin{array}{c}2.11 \\
(0.9-5.0)\end{array}$ & $\begin{array}{c}0.60 \\
(0.3-1.1)\end{array}$ \\
\hline$>9$ & $\begin{array}{c}38.89 \\
(17.3-64.3)\end{array}$ & $\begin{array}{c}84.21 \\
(60.4-96.6)\end{array}$ & $\begin{array}{c}2.46 \\
(0.8-8.1)\end{array}$ & $\begin{array}{c}0.73 \\
(0.5-1.1)\end{array}$ \\
\hline$>10$ & $\begin{array}{c}0 \\
(0.0-18.5)\end{array}$ & $\begin{array}{c}100 \\
(82.4-100.0)\end{array}$ & & $\begin{array}{c}1 \\
(1.0-1.0)\end{array}$ \\
\hline
\end{tabular}

was also reported in a previous study, may as well be results from prior antibiotic use. ${ }^{17-18}$

This study showed that IgM anti S. typhi serologic test had a poor AUC when cut-off value $\geq 4$ was used, while highest AUC was demonstrated on cut-off value $>8$. Sensitivity was found to be good as reported in previous studies in all age groups6 and children group ${ }^{10,11}$ reflecting the high number of positive result when the disease is actually present. In contrast, its specificity was considered low; meaning that it would give a low number of negative results when the disease was actually not present. High sensitivity and low specificity of the test were also reported in the childrenpopulated study performed by Narayanappa, et al. ${ }^{11}$

This retrospective study was a hospitalbased study where most patients had previously visited the primary health care. Children with 1-14 days of fever were included because the best period of blood culture are the first few days of disease $\mathrm{e}^{14-16}$ and the best period of IgM anti S. typhi serologic test is the second week of disease. ${ }^{5,8}$ The facts that antibiotics were widely used prior to the admission of patients could make the number of study subjects even lower and impossible to conduct this study; thus, children with prior antibiotic use were not excluded. The number of bacteria and antibody are influenced by the time of disease. The best period for both blood culture and IgM anti S. typhi serologic test is different but specimen was taken only once. Perhaps, if specimens were taken twice within a week of interval, the results would differ in some ways. Both blood culture and IgM anti $S$. typhi test results are dependent on skills or accuracy of the performing staff as well as laboratory equipment. These might also affect the test results.

In conclusion, IgM anti $S$. typhi test of cutoff $>8$ performs better than cut-off $\geq 4$ in terms of AUC. The researcher suggests a further prospective diagnostic study that considers the time of specimen collection and antibiotic usage, perhaps a secondary health care-based study. Clinicians should consider the cut-off values when making the diagnosis of typhoid fever in children-populated practical setting.

\section{References}

1. Mogasale V, Maskery B, Ochiai RL, Lee JS, Mogasale VV, Ramani E, et al. Burden of typhoid fever in low-income and middleincome countries: a systematic, literaturebased update with risk-factor adjustment. Lancet Glob Health. 2014;2(10):570-80.

2. Badan Penelitian dan Pengembangan Kesehatan. Riset kesehatan dasar 2007. Jakarta (Indonesia): Depkes RI; 2008. p. 107-9.

3. Bhutta ZA. Salmonella. In: Kliegman RM, Stanton BF, Geme JWS, Schor NF, Behrman 
RE, editors. Nelson textbook of pediatrics. 19th ed. Philadelphia: Saunders; 2011. p. 948-58.

4. Dutta S, Sur D, Manna B, Sen B, Deb A, Deen J, et al. Evaluation of new-generation serologic tests for the diagnosis of typhoid fever: data from a community-based surveillance in Calcutta, India. Diagn Microbiol Infect Dis. 2006;56(4):359-65.

5. Abdoel TH, Pastoor R, Smits HL, Hatta M. Laboratory evaluation of a simple and rapid latex agglutination assay for the serodiagnosis of typhoid fever. Trans R Soc Trop Med Hyg. 2007;101(10):1032-8.

6. Kawano RL, Leano SA, Agdamag DMA. Comparison of serological test kits for diagnosis of typhoid fever in the Philippines. J Clin Microbiol. 2007;45(1):24-7.

7. Naheed A, Ram PK, Brooks WA, Mintz ED, Hossain MA, Parsons MM, et al. Clinical value of Tubex ${ }^{\mathrm{TM}}$ and Typhidot ${ }^{\circledR}$ rapid diagnostic tests for typhoid fever in an urban community clinic in Bangladesh. Diagn Microbiol Infect Dis. 2008;61(4):381-6.

8. Pastoor R, Hatta M, Abdoel TH, Smits HL. Simple, rapid, and affordable pointof-care test for the serodiagnosis of typhoid fever. Diagn Microbiol Infect Dis. 2008;61(2):129-34.

9. Siba V, Horwood PF, Vanuga K, Wapling J, Sehuko R, Siba PM, et al. Evaluation of serological diagnostic tests for typhoid fever in Papua New Guinea using a composite reference standard. Clin Vaccine Immunol. 2012;19(11):1833-7.

10. Rahman M, Siddique AK, Tam FC-H, Sharmin S, Rashid H, Iqbal A, et al. Rapid detection of early typhoid fever in endemic community children by the TUBEX® 09antibody test. Diagn Microbiol Infect Dis. 2007;58(3):275-81.

11. Narayanappa D, Sripathi R, Jagdishkumar
K, Rajani HS. Comparative study of dot enzyme immunoassay (Typhidot-M) and Widal test in the diagnosis of typhoid fever. Indian Pediatric. 2010;47(4):331-3.

12. World Health Organization. Pocket book of hospital care for children: guidelines for the management of common childhood illnesses. Geneva: WHO Library Cataloguing Data; 2013.

13. Setiabudi D, Madiapermana K. Demam tifoid pada anak usia di bawah 5 tahun di bagian ilmu kesehatan anak RS Hasan Sadikin Bandung. Sari Pediatri. 2005;7(1):9-14.

14. Ochoa T], Santisteban-Ponce J. Salmonella. In: Cherry JD, Harrison GJ, Kaplan SL, Steinbach WJ, Hotez PJ, editors. Feigin and Cherry's textbook of pediatric infectious diseases. $7^{\text {th }}$ ed. USA: Elsevier; 2014. p. 1491-509.

15. Parry CM, Wijedoru L, Arjyal A, Baker S. The utility of diagnostic tests for enteric fever in endemic locations. Expert Rev Anti Infect Ther. 2011;9(6):711-25.

16. Moore CE, Pan-Ngum W, Wijedoru LPM, Sona S, Nga TVT, Duy PT, et al. Evaluation of the diagnostic accuracy of a typhoid IgM flow assay for the diagnosis of typhoid fever in Cambodian children using a bayesian latent class model assuming an imperfect gold standard. Am J Trop Med Hyg. 2014;90(1):114-20.

17. Brooks WA, Hossain A, Goswami D, Sharmeen AT, Nahar K, Alam K, et al. Bacteremic typhoid fever in children in an urban slum, Bangladesh. Emerg Infect Dis. 2005;11(2):326-9.

18. Siddiqui FJ, Rabbani F, Hasan R, Nizami SQ, Bhutta ZA. Typhoid fever in children: some epidemiological considerations from Karachi, Pakistan. Int J Infect Dis. 2006;10(3):215-22. 